\title{
O ESTÁGIO CURRICULAR NA FORMAÇÃO DE PROFESSORES: REVISITANDO O DEBATE
}

\author{
M. E. B. OLIVEIRA* \\ Universidade do Estado do Rio Grande do Norte (UERN) ${ }^{*}$ \\ meyrester@yahoo.com.br
}

Submetido 10/03/2017 - Aceito 31/08/2017

DOI: $10.15628 /$ holos. 2017.5760

\section{RESUMO}

Neste trabalho busco problematizar o papel do estágio curricular na formação docente, a partir da análise dos sentidos produzidos sobre esta atividade no curso de Pedagogia da Faculdade de Educação/UERN. Assim, interrogo: que sentidos sobre o estágio são propostos no Projeto Pedagógico do Curso? Que traduções são produzidas pelos que vivenciam esta atividade acadêmica? Que sentidos são provisoriamente estabilizados? Com efeito, apresento uma análise sobre formações discursivas de professores e alunos do curso em foco, identificando os núcleos de sentido e recorrência na significação que permitem compreender a estabilização de sentidos sobre o estágio curricular supervisionado. Para tanto, tomo como material empírico o Projeto Pedagógico do Curso, visando à análise da concepção e proposta de estágio e textos produzidos por alunos e professores do curso de Pedagogia por ocasião do I Seminário de Avaliação da
Formação do Pedagogo no Curso de Pedagogia da UERN - SEMAPED. O trabalho se articula com a pesquisa que venho desenvolvendo no âmbito do curso de Doutorado em Educação na qual busco compreender no processo de produção da política curricular a micropolítica institucional, as produções de sentidos e as traduções para as políticas de formação de professores. Apoiandome na compreensão do currículo como espaço fronteiriço de enunciação cultural (MACEDO, 2006; FRANGELLA, 2009) e como um discurso que constrói sentidos (LOPES e MACEDO, 2011), proponho pensar que o currículo constitui o conjunto de discursos que estabelece sentidos, sempre contingentes, num movimento contínuo de construção/desconstrução, não havendo, portanto, a possibilidade de correspondência entre proposta e prática, tampouco de bloquear a significação.

PALAVRAS-CHAVE: Estágio Curricular. Formação de Professores. Traduções. Produções de Sentidos.

\section{THE CURRICULAR INTERNSHIP IN TEACHERS' FORMATION: REVISITING THE DEBATE}

\begin{abstract}
In this work I try to problematize the role of curricular internship in teacher's formation, from the analysis of the senses produced on this activity in the Pedagogy course of the School of Education / UERN. So, I question: what senses about the internship are proposed in the Pedagogical Project of the Course? What translations are produced by those who experience this academic activity? What meanings are provisionally stabilized? In effect, I present an analysis of discursive formations of teachers and students of the course in focus, identifying the nuclei of sense and recurrence in the meaning that allow to understand the stabilization of senses about the supervised curricular internship. Therefore, I take as empirical material the Pedagogical Project of the Course, aiming at the analysis of the conception and proposal of internship and texts produced by students and teachers of the course of Pedagogy on the occasion of the First Seminar of
\end{abstract}

Evaluation of Pedagogue Formation in the Course of Pedagogy of UERN - SEMAPED. The work is articulated with the research that I have been developing in the ambit of the Doctoral Degree in Education, in which I try to understand in the process of production of the curricular policy the institutional micropolitics, the productions of senses and the translations for the policies of teachers' formation. Supporting me in understanding the curriculum as border space of cultural enunciation (MACEDO, 2006; Frangella, 2009) and as a discourse that builds senses (LOPES and MACEDO, 2011), I propose to think that the curriculum constitutes the set of discourses that establishes senses , always contingent, in a continuous movement of construction / deconstruction, so there is no possibility of matching proposal and practice, nor blocking the significance.

KEYWORDS: Curricular Internship. Teachers' Formation. Translations. Productions of Senses. 


\section{INTRODUÇÃO}

O presente trabalho aprofunda discussões e estudos que tenho realizado nos últimos anos sobre o estágio curricular supervisionado, o que justifica a ideia implícita no texto de retorno ao debate. Tal intento se faz a partir do entrecruzamento das reflexões advindas de experiências vivenciadas no Fórum Integrado de Estágio e Licenciaturas (FIEL) com os resultados parciais de um estudo realizado no âmbito do projeto de doutoramento em Educação, que tem como foco um espaço-tempo específico de produção curricular - a Faculdade de Educação da Universidade do Estado do Rio Grande do Norte (FE/UERN) - tomada como locus produtivo de micropolíticas. Um dos objetivos da pesquisa é focalizar os significantes que assumem maior importância na proposta curricular do curso, tendo em vista o exame das significações que vão sendo estabilizadas. Vale ressaltar que na análise da constituição discursiva sobre a formação no curso de Pedagogia percebi que o significante estágio assumiu um papel privilegiado, tanto no processo de elaboração da proposta curricular, quanto na sua institucionalização. Esse fato me levou a questionar: que significações essa atividade vem assumindo na formação do Pedagogo da UERN? Que traduções são produzidas pelos que vivenciam esta atividade acadêmica? Que sentidos são provisoriamente estabilizados?

Na perspectiva de responder as questões a que me propus apoio-me na compreensão do currículo como espaço fronteiriço de enunciação cultural (MACEDO, 2006; FRANGELLA, 2009) e como um discurso que constrói sentidos (LOPES e MACEDO, 2011). Ao conceber o currículo como espaço enunciativo e, por conseguinte, como prática de significação, estou assumindo que este não se esgota na formulação de um documento ou mesmo na prática docente. Nesses termos, o currículo constitui o conjunto de discursos que estabelece sentidos, sempre contingentes, num movimento contínuo de construção/desconstrução.

Em função das questões norteadoras e do referencial que informa o presente estudo organizei o trabalho em duas partes. Na primeira apresento algumas reflexões suscitadas nas discussões e estudos promovidos pelo FIEL no tocante a articulação discursiva de uma concepção de estágio com vistas à superação da dicotomia teoria e prática. Na segunda parte apresento de forma sintética a concepção e proposta de estágio no curso de Pedagogia da UERN, bem como as traduções e produções de sentido presentes nos trabalhos analisados. Por último, a guisa de conclusão, interrogo o papel do estágio na formação dos professores, tomando como referência os sentidos evidenciados nas produções analisadas. 


\section{O ESTÁGIO EM DEBATE: PARA ALÉM DE UMA CONCEPÇÃO INSTRUMENTAL}

No âmbito da UERN o Fórum Integrado de Estágio e Licenciaturas (FIEL) tem atuado em parceria com a Pró-Reitoria de Ensino de Graduação (PROEG), como espaço de reflexão e proposição de políticas que visam à melhoria do ensino de graduação. Criado em 2003, sua composição abrange professores dos diversos cursos de Licenciatura do campus central e dos campi avançados, além de representantes da PROEG, que têm assumido a coordenação dos trabalhos. As reuniões, de caráter itinerante, tendo em vista que cada reunião é sediada em uma das unidades acadêmicas (campi avançados situados em outros municípios do estado), configuram-se como espaços de formação e autoformação, por propiciarem momentos ricos em diálogos que visibilizam a pluralidade, e ao mesmo tempo, a singularidade de cada curso, de cada prática, expressas nas falas dos professores representantes. Nesta polifonia evidenciam-se os confrontos e divergências de posicionamentos, os deslocamentos, as reconfigurações, as tensões entre interesses que, por sua vez, evocam concepções filosóficas, epistemológicas, políticas e pedagógicas constituindo-se, portanto, num espaço profícuo de discussões sobre as políticas e práticas pedagógicas nos contextos macro e micro.

Dentre os temas de maior interesse no escopo das discussões do FIEL figura o estágio curricular supervisionado, ficando sob a responsabilidade deste fórum a proposição de diretrizes norteadoras para o estágio. $O$ processo de discussão, que se estendeu por um período de aproximadamente dois anos, culminou com a aprovação da Resolução n. 036/2010 que instituiu normas disciplinares para o estágio curricular supervisionado nos cursos de formação de professores da instituição.

Cumpre esclarecer que os cursos de licenciatura da Universidade vivenciaram um processo de reestruturação curricular, desencadeado a partir de $2002 \mathrm{com}$ a publicação das Diretrizes Curriculares Nacionais para a Formação de Professores (DCN FP), por meio das Resoluções do Conselho Nacional de Educação CNE/CP no 01 e 02/2002, mas que só veio a se intensificar a partir de 2005, em virtude do prazo estabelecido pelo Ministério da Educação (MEC), por meio da Resolução CNE/CP no 02 de 27 de agosto de 2004, que adiava o prazo para adequação dos cursos de licenciatura às DCN.

Nessa perspectiva,

(OLIVEIRA e OLIVEIRA, 2013, p. 04) As DCN foram assumidas no discurso institucional, particularmente da PROEG, como um avanço, no sentido de que proporcionariam uma melhoria da qualidade dos cursos, à medida que instigavam a repensar e reconfigurar seus modelos formativos, de modo a se adequarem às demandas do contexto contemporâneo. Além disso, vislumbravam-se as referidas propostas como uma forma de superar parte dos problemas históricos enfrentados pelos cursos de formação de professores, entre os quais destacam-se o perfil bacharelesco e o distanciamento do objeto da formação. Assim, empreendeu-se um esforço, com o intuito de adequar as propostas pedagógicas dos cursos não só às DCN, como também às necessidades específicas de cada curso.

Em decorrência desse processo os cursos foram instados a repensar suas propostas formativas, as concepções pedagógicas que embasavam as estruturas curriculares e, consequentemente o perfil profissional desejado. Por conseguinte, os ingressantes nos cursos de formação de professores para o semestre 2006.1, na UERN, passaram a ter sua formação regulamentada pelas DCN FP.

Como resultado desse movimento Oliveira e Oliveira (2013) destacam algumas incorporações das propostas das DCN nos Projetos Pedagógicos dos Cursos (PPC), dentre os 
quais: ampliação da carga horária total dos cursos, que passou a ser igual ou superior a 2800 horas; ampliação da formação pedagógica, muito embora não se apresente uma definição concisa a esse respeito, tampouco se conseguiu chegar a um consenso sobre quais disciplinas constituem a base dessa formação; a inclusão da prática como componente curricular, que assumiu diferentes formatos nos diversos cursos, e a exigência de um trabalho de conclusão de curso. A esse respeito, destacam "O Trabalho de Conclusão de Curso - TCC passou a ser requisito para a conclusão da maioria dos cursos, ancorada na ideia da formação do professor pesquisador, outra grande referência que perpassou a reformulação curricular" (OLIVEIRA e OLIVEIRA, 2013, p.09).

No que concerne ao estágio observou-se uma ampliação da carga-horária dessa atividade, bem como sua diluição a partir da segunda metade do curso. A partir de uma análise comparativa das propostas de estágio dos cursos, as autoras, apontam a presença de propostas diferenciadas para a vivência do estágio, tanto na distribuição da carga horária, quanto na proposição das etapas de seu desenvolvimento.

Com efeito, se pode inferir que os cursos haviam ampliado a carga horária do estágio, todavia, isso não implicava necessariamente na ressignificação das práticas. Estava aberto então, um campo de significação, no qual se poderia intervir com vistas a hegemonização de determinados sentidos. Influenciados pela perspectiva de estágio defendida por Pimenta e Lima (2004), que definem o estágio como campo de produção de conhecimento e eixo articulador da formação, as discussões do fórum tinham como propósito estabilizar estes sentidos como norteadores das práticas de estágio na instituição. Tal intento se justifica primeiramente em função de que a resolução de estágio vigente datava de 1998, portanto, não contemplava as mudanças preconizadas pelas DCN FP, e em segundo lugar, pode se destacar as questões suscitadas pelos professores orientadores/supervisores e coordenadores as quais requeriam especial atenção e demandavam encaminhamentos urgentes, tais como: ausência de procedimentos de "padronização" entre os diversos cursos e campi; pouco conhecimento sobre o campo de estágio e suas reais possibilidades; distanciamento entre a Universidade e as escolas campo de estágio; incompatibilidade entre o calendário institucional e o das escolas de Educação Básica; ausência de convênios entre as instituições campo de estágio e a universidade, gerando certa instabilidade na relação e indefinição quanto ao local de realização do estágio: sede ou fora de sede.

O desafio assumido pautou-se, então, em pensar/propor uma concepção de estágio que viesse a problematizar o caráter instrumental de que, muitas vezes se reveste tal atividade, para além de uma visão que o reduz a aplicação de teorias apreendidas ao longo do curso e ao desenvolvimento de habilidades instrumentais, consideradas, a priori, necessárias ao bom desempenho docente, ou seja, ao como fazer.

A partir desse entendimento, a concepção de estágio articulada e construída nas discussões do FIEL, aponta para o estágio como campo de conhecimento teórico-prático e interdisciplinar, para onde convergem diferentes tipos de conhecimentos científicos provenientes das distintas áreas de conhecimento e das experiências vivenciadas no decurso da formação. Nessa direção o estágio passa a ser compreendido como um eixo da formação, intrinsecamente relacionado às demais ações definidas na proposta pedagógica do curso, sendo concebida como atividade teórica de conhecimento, fundamentação, diálogo e intervenção na realidade, mas também como atividade instrumentalizadora da práxis docente. 
$\mathrm{Na}$ resolução, também foram definidos os eixos metodológicos que deverão nortear o estágio: atuação interdisciplinar; articulação teoria-prática; investigação/intervenção; resolução de situações-problemas e reflexão sobre a atividade profissional (RESOLUÇÃO N. 36/2010). Além de apresentar concepções basilares para o desenvolvimento do estágio a resolução em apreço apontava algumas regulamentações em relação aos procedimentos, modalidades, supervisão e avaliação, uma vez que se entendia que "o desenvolvimento do estágio precisa ser orientado por procedimentos definidos que visem ao melhor aproveitamento dos momentos destinados a disciplina" (KENSKI, 1991, p.39).

Considerando a produção de documentos normativos como uma micropolítica institucional, fruto do entrelaçamento de diferentes contextos de produção, nos quais sentidos por vezes distintos se hibridizam, na medida em que resultam de negociações, de interesses e disputas que influenciam todo processo discursivo, proponho pensar a Resolução em apreço como um texto político. Nesse prisma, compreendo que:

(LOPES e MACEDO, 2011, p. 259) Como texto coletivo, o texto político é produto de acordos realizados em diferentes esferas, envolvendo, inclusive, a troca constante de sujeitos autores. Assim, abrem-se espaços de ação, na medida em que o lugar em que as políticas são codificadas é também ele instável e ambíguo.

Tal entendimento deriva de uma concepção de política como produção cultural, construída mediante processos que envolvem negociações, traduções e disputas de sentidos em diferentes contextos. Distanciando-me do entendimento de que as políticas são um guia de orientação para a prática, assumo a compreensão dos contextos como arenas atravessadas por disputas e embates e o texto político como um discurso híbrido, permeado por ambiguidades que o constituem como discurso político, cujo fechamento da significação é sempre adiado.

\section{O ESTÁGIO CURRICULAR NO CURSO DE PEDAGOGIA: SENTIDOS EM DISPUTA}

Tendo como objetivo analisar formações discursivas de professores e alunos do curso de Pedagogia da Faculdade de Educação/UERN, identificando os núcleos de sentido e recorrência na significação que permitem compreender a estabilização de sentidos sobre o estágio curricular supervisionado, tomo como material empírico de análise, para este trabalho, o Projeto Pedagógico do curso de Pedagogia da Faculdade de Educação, campus Mossoró e textos produzidos por alunos e professores do referido curso por ocasião do I Seminário de Avaliação da Formação do Pedagogo no Curso de Pedagogia da UERN - SEMAPED. Sem pretender abarcar todas as nuanças de um campo tão complexo, apresento de forma breve alguns aspectos que compõem a minha análise.

\subsection{O estágio no Projeto Pedagógico do Curso de Pedagogia}

Parto da compreensão do Projeto Pedagógico do Curso como tentativa de representação da política para a formação do pedagogo, na medida em que institui sentidos e projeta identidades. Com base na compreensão de que a produção curricular no curso de Pedagogia ocorre por meio da tradução das políticas de formação de professores, advogo que qualquer hegemonização de sentidos é sempre parcial e provisória, pois na medida em que não há possibilidade de acesso a um dado sentido original, o processo de significação não cessa (LOPES et al, 2013).

Assumo o pressuposto de que os sentidos das práticas já existentes no curso foram incorporados a atual proposta curricular, hibridizando-se aos sentidos propostos pelas Diretrizes Curriculares e às orientações institucionais. 
Coadunando-se com os referencias que orientaram as discussões desenvolvidas no FIEL, o estágio é apresentado na proposta pedagógica do curso em apreço como atividade instrumentalizadora da práxis, não se reduzindo, porém, a mera aplicação de técnicas e/ou conhecimentos. Nesses termos é concebida como uma atividade teórico-prática, desenvolvida em sintonia e interação com os demais componentes do currículo.

Nessa perspectiva, o estágio não pode ser compreendido sem que se estabeleça uma relação com a finalidade do curso e o perfil profissional que se pretende formar "reflexivo, pesquisador, comprometido com o pensar/agir diante das problemáticas educacionais evidenciadas nos espaços escolares e não escolares lócus de ação profissional do futuro licenciado" (UERN, 2012, p. 54). De acordo com a Proposta Pedagógica do Curso a atividade de estágio estrutura-se em três momentos:

O Estágio I, que deverá ser realizado em unidades de educação infantil compreendendo:

(FACULDADE DE EDUCAÇÃO, 2012, p. 56) o estudo, a análise, a problematização, a reflexão e a elaboração de proposição de soluções às situações de ensinar, aprender e elaborar, executar e avaliar projetos de ensino, não apenas na sala de aula mais também na escola e na sua relação com a comunidade.

O Estágio II, voltado para os espaços escolares nos anos iniciais do ensino fundamental, "Consiste no desenvolvimento de práticas pedagógicas - execução de projetos - que propiciem situações e experiências práticas que aprimorem a formação e atuação profissional, preferencialmente vinculado a sala de aula" (FE, 2012, p. 57).

O Estágio III, possibilita ao aluno optar por ampliar uma das experiências que vivenciou nos estágios anteriores ou vivenciar o campo de atuação do pedagogo nos espaços não escolares. A proposta é possibilitar ao aluno oportunidades de:

(FACULDADE DE EDUCAÇÃO, 2012, p. 58) vivenciar a construção de uma visão mais ampla de atuação na escola, na organização do ensino, na comunidade e na sociedade, tendo a flexibilidade de dar continuidade - aprofundando e ou ressignificando sua compreensão teóricoprática - no espaço escolar, ou conhecer/pesquisar outros espaços que demandem o trabalho pedagógico.

Observam-se na proposta alguns elementos que se articulam com as concepções que inspiraram a Resolução n.36/2010, dentre as quais: o estágio como campo de produção de conhecimento e de articulação entre teoria e prática; a ideia do estágio como elemento que poderá viabilizar a tríade ensino, pesquisa e extensão; a noção de que o estágio funciona como via de aproximação entre escola e universidade e como momento de aprimoramento das competências e habilidade profissionais.

\subsection{Produzindo sentidos sobre o estágio}

Meu interesse aqui é focalizar as produções discursivas de professores e alunos do curso de Pedagogia visando a interpretar as leituras/sentidos para a formação do pedagogo, tomando como referência o currículo vigente e o significante estágio. Parto da análise dos textos produzidos por ocasião do I SEMAPED, evento realizado em 2012, que tinha como objetivo discutir questões sobre a pedagogia, a identidade e o espaço de atuação do pedagogo, contribuindo assim para a avaliação da implementação do Projeto Pedagógico do Curso, em vigor a partir de 2007. Participaram do seminário alunos, professores, gestores da educação básica e superior, dentre outros profissionais da educação e de instituições que demandam o trabalho pedagógico, na perspectiva de suscitar o debate sobre os conceitos e princípios que fundamentam as práticas formativas desenvolvidas no curso, bem como dialogar com esses 
profissionais que representam os campos de atuação do pedagogo. Com efeito, meu foco recaiu sobre os trabalhos apresentados no GT 02 - Estágio supervisionado no curso de pedagogia da UERN, composto por 21 textos, que englobam produções de alunos, de professores e produções conjuntas entre alunos e professores dos campi Mossoró, Assu, Pau dos Ferros e Patu, onde o curso é ofertado.

Os textos analisados são tomados como discursos, compreendidos aqui enquanto produções de sentidos que criam um "ser" para o currículo, na medida em que esses sentidos passam a ser partilhados e aceitos. Nesse entendimento o discurso não se restringe à fala dos sujeitos, mas se constitui na elaboração de sentidos construídos nas interações que se estabelecem entre as pessoas. Assumo também como premissa que esses sentidos são produzidos de forma contingente e precária num fluxo contínuo de negociação e que, portanto, estão sempre em disputa.

De modo geral, os textos, refletem sobre as atividades realizadas no decorrer do estágio e suas contribuições para a formação docente, no âmbito dos espaços escolar e não escolar, sendo possível encontrar uma variedade considerável de abordagens, entre as quais: a descrição de projetos de intervenção; a percepção dos alunos estagiários sobre as contribuições do estágio; propostas alternativas de desenvolvimento do estágio, bem como atividades de pesquisa desenvolvidas no campo de atuação. Ao escreverem textos sobre as experiências vivenciadas no decorrer do estágio, professores e alunos (re)constroem sentidos sobre este significante, atribuindo-Ihes significações por vezes antagônicas.

Em uma análise inicial se verifica que os artigos apresentam diferentes concepções sobre o tema, mas não se pode negar que há também muitos encontros nesses modos de conceber o estágio, percebendo-se inclusive uma hibridização de sentidos, o que por sua vez, evidencia certa ambiguidade, igualmente presente nos discursos que circulam em diferentes contextos da produção curricular.

Apresento a seguir alguns excertos que permitirão problematizar/interpretar os sentidos produzidos sobre o estágio no curso de Pedagogia. O recorte se deu na perspectiva de tentar compreender o papel do estágio, suas contribuições para a formação de professores e os sentidos que foram/são produzidos e estabilizados.

(T01) O estágio como uma atividade muito além do que só uma disciplina obrigatória pela qual devemos passar, mas como uma forma de colocarmos nossa fundamentação teórica em prática, além de ter ainda a possibilidade de fazermos o que tanto gostamos e pretendemos fazer diariamente num futuro muito próximo [...].

(T02) O estágio não só pode como deve ser visto como um campo de conhecimentos que possibilita ao aluno encontrar-se na profissão, descobrir sua identidade pedagógica e realmente perceber se esta e a profissão que quer exercer no futuro.

(T04) Esta prática do Estágio Supervisionado III em um espaço não escolar nos proporcionou saberes que vão além daqueles restritos a sala de aula, uma vez que o trabalho com pessoas com deficiência nos fez valorizar cada vez a amplitude da profissão de pedagogo e, sobretudo o seu exercício enquanto mediador de conhecimento.

(T06) O Estágio Supervisionado I contribui significativamente para a formação do pedagogo, uma vez que possibilita o contato com a realidade na qual irá se inserir. Oportunizando o desenvolvimento de suas habilidades pedagógicas, assim como a relação simultânea entre teoria e prática. 
(T07) O estágio contribuiu bastante para uma descoberta e uma aplicação de sentidos ao que se estuda na universidade, se atribuir valores ao que os autores da área abordam em suas obras.

(T10) Ressaltamos a relevância do Estagio Supervisionado II em nossa formação profissional e acadêmica [...] Experiência que proporcionou a junção teoria e prática [...].

(T12) O estágio contribui para a busca dessa identificação com a docência, é justamente no estágio que você vivencia na prática, e percebe o quanto toda teoria auxilia na busca da melhor estratégia para situações complexas no cotidiano de uma sala de aula.

(T17) A finalidade do estágio é proporcionar ao estudante experiência prática na sua formação, concedendo-lhe complementação do ensino aprendizagem seja ele de maneira formal ou não formal. Através do estágio é possível também que o Pedagogo ressignifique seus saberes e produza novos conhecimentos.

(T19) A experiência do estágio constituiu um momento de reflexão e aprofundamento do conhecimento, uma vez que, fizemos a articulação entre teoria e prática, como também pudemos vivenciar de perto as características positivas e negativas do trabalho pedagógico.

A análise dos núcleos de sentido permite identificar as concepções de estágio presentes nos textos: o estágio como espaço de formação, de reflexão e de produção de conhecimentos sobre a escola e sobre a profissão; o estágio como espaço de pesquisa e de produção do conhecimento; o estágio enquanto articulação dos saberes teóricos com os práticos e o estágio como espaço de aplicação da teoria, isto é, o momento da prática.

No decorrer dos textos os autores vão explicitando o que consideram contribuições dessa atividade para a formação, destacando entre elas: a construção da identidade docente; o desenvolvimento de saberes, habilidades e competências; o contato e diagnóstico da realidade; a proposição de alternativas inovadoras para as escolas. Todavia, prevalece uma ideia de estágio como espaço, momento ou possibilidade de articulação entre diversos pares binários que compõem a formação, a saber: teoria/prática; formação inicial/continuada; universidade/campo de estágio; ensino/pesquisa; disciplinas gerais/específicas.

Esse modo de conceber esta atividade implica alguns desdobramentos para a formação. $O$ primeiro diz respeito à hipervalorização do estágio - o estágio como o centro da formação. Isso remete a uma percepção deste componente como a "tábua de salvação", remédio para todos os males, solução para as fragmentações, lacunas e fragilidades que não conseguiram ser superadas, ou pelo menos, enfrentadas no decorrer da formação. Com efeito, a experiência do estágio deixa de ser percebida como uma entre tantas outras atividades acadêmicas, que inegavelmente tem um papel relevante na formação, para ser assumida como o eixo em torno do qual devem orbitar todas as demais. Não obstante, sob essa via é muito comum o estágio se tornar o inverso, ou seja, de remédio transmuta-se em veneno, na medida em que não consegue atender ou cumprir todas as demandas estabelecidas a priori. O segundo desdobramento desse modo de conceber o estágio é a acentuação dos binarismos, que poderá vir a ocorrer em consequência de uma ideia de articulação como mera reunião de elementos distintos. Neste caso, os pares binários continuam intactos, não alteram suas propriedades, apenas se aproximam, mas as fronteiras permanecem incólumes, posicionadas hierarquicamente. Considero que essa ideia aditiva de articulação não desestabiliza a polarização, mas ao contrário a acomoda, quando propõe como alternativa a justaposição entre os polos. 
Como desdobramento da ideia de articulação como junção, chamo atenção para o destaque dado à articulação teoria-prática, que prevaleceu na grande maioria dos trabalhos. Quero ressaltar alguns aspectos em torno dessa ideia: o primeiro é em relação à noção do que chamamos realidade. Em alguns dos trabalhos analisados predominava uma percepção da realidade como algo estabelecido a priori, da qual os professores/pesquisadores/alunos se aproximam, descrevem, analisam e produzem conclusões para supostamente melhorar a prática. A prática é pensada como central na formação de professores, mas ao mesmo tempo se reforça um sentido da prática como algo adicional, complementar da formação docente.

(ABREU; LOPES, 2009, p. 88) No relevo à prática na formação, a disciplina de Estágio Curricular ou Prática de Ensino passa a ser explorada em muitos dos textos, [...], como uma disciplina nevrálgica para a formação profissional. [...] sendo identificada como "a disciplina" que tem as condições para realizar tal relação [teoria-prática], especialmente por ser nela que se apresenta a possibilidade de imersão no cotidiano da profissão docente.

Um segundo aspecto, diz respeito à tônica de prescritividade e de exemplaridade que aparece em alguns relatos de experiências, que não raro apresentam recomendações de forte cunho prescritivo endereçadas às instituições campo de estágio. Como se, somente a universidade fosse o lugar da inovação, terminando assim por desconsiderar as práticas cotidianas das escolas e consagrar estas como o lugar da reprodução de saberes produzidos por especialistas.

Por fim, quero realçar certa tendência a autonomização da instância da prática, por vezes reduzida ao que existe no cotidiano, fruto de uma visão que concebe a teoria como um guia para a ação e como um referencial supostamente neutro, não contaminado pelas fragilidades da prática. É preciso considerar também, que apesar da aparência uníssona sobre a prática como questão central da profissionalização docente, os sentidos e as demandas que se apresentam são distintos e por vezes, ambíguos.

\section{4 À GUISA DE CONCLUSÃO}

Problematizar os sentidos produzidos sobre o estágio na formação de professores suscita repensar como se constituíram/constituem as formações discursivas no curso de Pedagogia em estudo e que articulações possibilitaram/possibilitam dadas estabilizações. Ao pensar sobre o estágio não o coloço num espaço central, privilegiado, nem tampouco, desconheço sua relevância na formação. Nesses termos, vislumbro-o como um espaço-entre diferentes contextos e diferentes saberes; um espaço-tempo de composição e recomposição contínua, de interseção, de entrecruzamentos em que as fronteiras são tênues. A fronteira aqui entendida não como o que delimita, restringe e demarca os limites geográficos, mas como espaço em que sujeitos distintos interagem, tendo por referência seus diferentes pertencimentos e essa interação é um processo cultural que ocorre num lugar-tempo, que pode ser a escola, a universidade, a comunidade. 


\section{REFERÊNCIAS}

ABREU, Rosane Gomes de; LOPES, Alice Casimiro. (2009). Sentidos da prática nas políticas de currículo para a formação de professores. Currículo sem Fronteiras, v.9, n.2, pp.79-99, Jul/Dez.

BRASIL. Resolução CNE/CP no 02 de 27 de agosto de 2004. Adia o prazo previsto no Art. 15 da Resolução 1/2002 que Institui Diretrizes Curriculares Nacionais para a Formação de Professores da Educação Básica, em nível superior, curso de licenciatura, de graduação plena. Brasília: DF.

FACULDADE DE EDUCAÇÃO. (2012). Projeto Pedagógico do Curso de Pedagogia. UERN/FE: Mossoró.

FRANGELLA, Rita de Cássia. (2009). Currículo como local de cultura: enunciando outras perspectivas em diálogo com Homi Babba. GT 12 Currículo. 32ํㅡ Reunião Anual da ANPED: Caxambu.

KENSKI, Vani Moreira. (1991). A vivência escolar dos estagiários e a prática de pesquisa em estágios supervisionados. IN: FAZENDA, Ivani Catarina Arantes [et all]; PICONEZ, Stela C. Bertholo (Coord.). A prática de ensino e o estágio supervisionado. Campinas-SP: Papirus.

LOPES, Alice C. et al. (2013). Da recontextualização à tradução: investigando políticas de currículo. Currículo sem Fronteiras, v. 13, n. 3, p. 392-410, set./dez.

LOPES, Alice Casimiro; MACEDO, Elizabeth. (2011). Teorias de currículo. São Paulo: Cortez.

OLIVEIRA, Marcia Betania de; OLIVEIRA, Meyre-Ester Barbosa de. (2013). A produção curricular nos cursos de licenciatura da UERN: Recontextualização das políticas de formação de professores? VII Seminário Internacional - As Redes Educativas e as Tecnologias: transformações e subversões na atualidade. Anais. Rio de Janeiro: UERJ.

PIMENTA, Selma Garrido; LIMA, Maria Socorro Lucena. (2004). Estágio e Docência. São Paulo: Cortez.

UNIVERSIDADE DO ESTADO DO RIO GRANDE DO NORTE. Resolução N³6/2010 - CONSEPE, de 11 de agosto de 2010. Aprova o Regulamento do Estágio Curricular Supervisionado nos Cursos de Licenciatura da Universidade do Estado do Rio Grande do Norte (UERN) e revoga a Resolução no 4/98- CONSEPE. Mossoró: RN. 